\title{
Research Article \\ Numerical Simulation on the Seepage Properties of Soil-Rock Mixture
}

\author{
Ning Zhao, ${ }^{1,2}$ Yingchao Wang $\mathbb{C}^{1,2}$ Bo Meng $\mathbb{D}^{2},{ }^{2}$ and Ning Luo ${ }^{2}$ \\ ${ }^{1}$ State Key Laboratory for Geomechanics and Deep Underground Engineering, China University of Mining and Technology, \\ Xuzhou, Jiangsu 221116, China \\ ${ }^{2}$ School of Mechanics \& Civil Engineering, China University of Mining and Technology, Xuzhou, Jiangsu 221116, China
}

Correspondence should be addressed to Yingchao Wang; wych12345678@126.com

Received 6 December 2017; Revised 28 July 2018; Accepted 8 August 2018; Published 22 November 2018

Academic Editor: Fernando Lusquiños

Copyright (c) 2018 Ning Zhao et al. This is an open access article distributed under the Creative Commons Attribution License, which permits unrestricted use, distribution, and reproduction in any medium, provided the original work is properly cited.

To reveal the mechanism of water inrush in a fault tunnel and study the influence of different structures on the seepage process, a filling structure composed of a soil skeleton (fixed particles), a movable particles phase, and a water phase is constructed to simulate the rock mass broken by the fault. Fluent software is used to simulate the migration of the water phase in three different filling structures under different initial water velocities and dynamic viscosities. The variation law of the seepage time with the initial water velocity and dynamic viscosity in the three types of filling structures is obtained. The research shows the following: (1) the looser the filling structure, the greater the influence of gravity on the water phase seepage; the more compact the filling structure, the greater the spread range of the water phase and the more uniform the spread of the water phase. (2) The seepage time decreases with the increase in the initial water velocity. The seepage time and initial water velocity can be fitted by an exponential function. The effect of initial water velocity on seepage time is much greater than that of the structure. (3) The seepage time is related to both the dynamic viscosity and the structure. The seepage time increases with the increase in dynamic viscosity.

\section{Introduction}

In recent years, with the vigorous development of the China's major transportation infrastructure, the depth of tunnel excavation has been continuously increasing, and the geological conditions for tunnel construction are complicated and changeable. When a deep-buried tunnel passes through the fault fracture zone, water inrush easily occurs. For example, the Liangshan tunnel of the Xiamen-Shenzhen railway passes through the L7-rich water fault fracture zone. When the 1 \# inclined shaft is constructed to DK96 + 505, 4 large-scale water inrush and mud burst disasters occurred, with a total amount of mud of approximately $30000 \mathrm{~m}^{3}$. During the construction of the Yonglian tunnel in Jiangxi Province, which passes through the fault fracture zone, 15 large-scale water inrush and mud burst disasters occurred. The amount of mud surpassed $5 \times 104 \mathrm{~m}^{3}$, and the construction period was delayed by 2 years. Water inrush has become one of the most serious problems in underground engineering [1-3]. According to statistics, in the process of tunnel construction, the major safety accidents caused by the water inrush disaster reached $80 \%$, of which $30 \%$ were caused by fault water inrush [4].

Many scholars devote themselves to the research of water inrush, and more and more methods are used to evaluate the risk of water inrush in tunnels [5-12]. The causes of water inrush in the tunnel are complicated, being not only affected by the geological conditions but also influenced by construction disturbances [13-16]. Fault water inrush is closely related to the development of the fault structure and the pores of the rock mass [17]. Therefore, the existence of faults does not mean that water inrush occurs immediately upon encountering faults. A large number of water inrush statistics show that many water inrush accidents in fault fracture zones have a hysteresis characteristic. This type of water inrush is often difficult to predict because of its hidden nature and hysteresis characteristics, introducing great hidden danger to the safety construction of tunnel 
engineering. Liu and Sun [18] reported that, under the longterm effect of confined water, the original fractures in the fault zone will soften and expand continuously, eventually leading to the formation of a large overwater channel, at which point delayed water inrush will occur. On the foundation of the establishment of a superior evaluation index and superior evaluation criteria, $\mathrm{Ni}$ and Luo [19] proposed that the dominant fault has an obvious shielding effect, which is the main reason for delayed water inrush. Wu et al. $[20,21]$ used FLAC3D software to simulate the whole process of the occurrence and development of the delayed water inrush and explained the mechanism of delayed water inrush. Based on the fluid-solid coupling theory, Li et al. $[22,23]$ studied the water inrush mechanism of coal seam floor faults and column collapse by numerical simulation and reproduced the whole process of the initiation of fractures, the activation of faults, and the formation of a groundwater inrush channel. Furthermore, the influence of the height of fault development and water pressure on the delayed time of water inrush was analyzed and discussed.

The soil-rock mixture is a common geotechnical material, composed of rocks, soil particles, and pores [24, 25]. It has the advantages of good resistance to compression performance, high shearing strength, and strong bearing capacity and has a wide range of applications. A range of scholars have conducted numerical simulations and laboratory tests to study the mesostructural characteristics of the soil-rock mixture [26-28]. The differences in the mechanical behavior of soil-rock mixture samples were studied in depth [29]. Based on the previous research studies [30-32], Yang et al. [33] studied the elastic modulus of the frozen soil-rock mixture in the freezing condition by establishing a suitable micromechanical model. Coli et al. [34] performed a largescale field test, and the test results show that there is a positive correlation between the internal friction angle and the rock block content. Zhang et al. [35] explored the effect of the grain size distribution on the mechanical properties of the soil-rock mixture and found that the interlocking and the breakage of the large rock blocks are two of the controlling factors of the mechanical properties of the soil-rock mixture.

The fault-filling medium is granular and permeable. In this paper, the filling structure composed of a soil-rock mixture is used to simulate the fault broken rock mass. After the fault is exposed, it takes a certain period of time from the infiltration instability of filling media to the final formation of the water inrush under the continuous action of construction and groundwater, which is the time-lag effect of water inrush. However, the current research studies on the mechanism of fault-delayed water inrush mainly focus on factors such as fault dip angle, aquifuge thickness, and the damage of floor strata $[36,37]$, whereas fewer research studies consider filling media and filling structures in the fault [38]. In this paper, the numerical simulation method is used to study the water migration in different structural pores of faultfractured rock mass. The impact factors related to the water inrush time are studied, and the mathematical relationship between the water inrush duration and the impact factor is given, thereby providing some new insights into the analysis of the mechanism of fault-delayed water inrush.

\section{Fluid-Solid Coupling Model of Granular Seepage Instability in the Fault- Filling Structure}

2.1. The Establishment of the Computational Model. The pores of the fractured rock mass are filled with a loose material, and the liquid exists in the pore space in a fluid state. Under the disturbance of tunnel excavation, the dynamic equilibrium state of groundwater is destroyed, the energy stored in the groundwater body is instantaneously released, and then, it is rapidly transported to the engineering free surface in the form of fluid. After the fault is exposed, the flowing water enters the pores of the fractured rock masses and causes the gradual loss of filling particles in the pores until the formation of the water inrush channel, eventually inducing a water inrush disaster. Under the action of water seepage, the static equilibrium state of filling particles is destroyed, the total mass of seepage particles increases gradually, and particles continue to be lost. With the loss of filling particles, the porosity and permeability coefficient of rock mass gradually become larger, which makes the rock mass more fragmented; in turn, the increasing fragmentation of the rock mass makes the pore space larger, and the loss rate of filling particles increases; this phenomenon is called the fluid-solid coupling effect [39].

In this paper, a numerical simulation is used to study the migration of water in three different structural pores of the fractured rock mass, and the seepage-flow transformation mechanism of the fillings in the pore of the fractured rock mass is revealed. The simulation model of the soil-rock mixture is based on previous studies [4, 39, 40], as shown in Figure 1. The filling structure can be regarded as consisting of the fixed particles phase (soil skeleton), the movable particles phase, and the water phase. The pores of the skeleton particles can provide the movable particles with the channels to be brought out, and the air exists between the movable particles; this system is a typical gas-liquid-solid three-phase system. The difference is that structure 1 has the largest distance between the fixed particle phases (soil skeleton) compared with structure 2 and structure 3 , and the structure is relatively loose; the distance between the fixed particle phases (soil skeleton) of structure 3 is the smallest. In this paper, the Euler three-phase flow model is used for the simulation study.

The basic assumption for the particle seepage model of the fractured rock mass is as follows $[4,39,41]$ :

(1) The soil skeleton does not deform during the seepage development of the infilling body; the movable particles phase and the water phase flow in the pores of the soil skeleton (fixed particles).

(2) The Reynolds number of the seepage field inside the filling body is between 1 and 10, which conforms to Darcy's law.

(3) The dissolution of the fluid to the skeleton and the collisions between the particles and skeleton and between particles and particles in the process of seepage are ignored. 


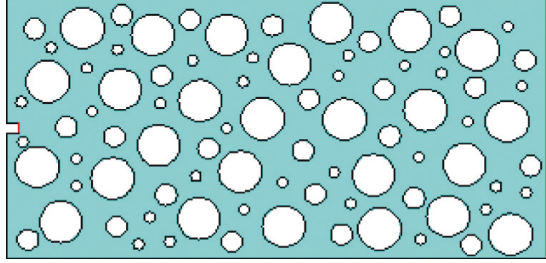

(a)

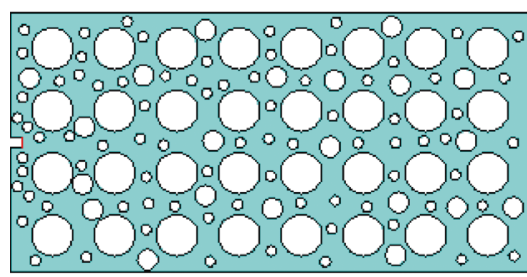

(b)

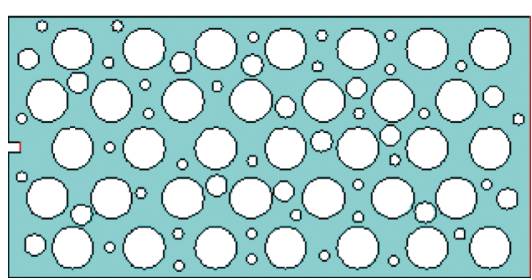

(c)

Figure 1: Numerical calculation model. (a) Structure 1. (b) Structure 2. (c) Structure 3.

(4) In the process of seepage, only the migration effect of the particles under the drag force of the water flow is considered, and the diffusion effect of the particle due to the concentration gradient change is ignored.

2.2. The Main Governing Equations. In the single-phase model, only one set of momentum and continuity conservation equations must be solved. To solve the multiphase model, additional conservation equations must be introduced. In this process, the original settings must be modified. This modification involves the introduction of multiphase volume fractions $\alpha_{1}, \alpha_{2}, \ldots, \alpha_{n}$ and the exchange mechanism of momentum between phases [42].

2.2.1. Volume Fraction. In the Eulerian model, the different phases of multiphase flow are considered to be interpenetrating and continuous. Therefore, the concept of the relative volume fraction is introduced to describe the proportion of each phase, which is expressed by $\alpha_{q}$. The volume fraction represents the space occupied by each phase, and each phase satisfies the laws of conservation of mass and momentum. The conservation equations of each phase can be obtained by using the local transient equilibrium of each phase or by using the mixed theory method.

The volume of $q$-phase is defined as follows:

$$
V_{q}=\int_{V} \alpha_{q} d V
$$

where $\sum_{q=1}^{n} \alpha_{q}=1$ and the effective density of $q$-phase is $\hat{\rho}_{q}=\alpha_{q} \rho_{q}$, in which $\rho_{q}$ is the physical density of the $q$-phase.

2.2.2. Mass Conservation Equation. The continuous equation of the $q$-phase is

$$
\frac{\partial}{\partial t}\left(\alpha_{q} \rho_{q}\right)+\nabla \cdot\left(\alpha_{q} \rho_{q} v_{q}\right)=\sum_{p=1}^{n} \dot{m}_{p q}
$$

where $\vec{v}_{q}$ is the speed of the $q$-phase and $\dot{m}_{p q}$ represents the mass delivered from the $p$-phase to the $q$-phase. From the mass conservation equation, $\dot{m}_{p q}=-\dot{m}_{q p}$, and $\dot{m}_{p p}=0$.

2.2.3. Momentum Conservation Equation. The momentum equation of the $q$-phase is

$$
\begin{aligned}
& \frac{\partial}{\partial t}\left(\alpha_{q} \rho_{q} V_{q}^{V}\right)+\nabla \cdot\left(\alpha_{q} \rho_{q} V_{q}^{V} v_{q}^{V}\right)=-\alpha_{q} \nabla p \\
& +\nabla \cdot \overline{\overline{\tau_{q}}}+\sum_{p=1}^{n}\left(\stackrel{V}{R_{p q}}+\dot{m}_{p q}{ }^{V} v_{p q}\right) \\
& +\alpha_{q} \rho_{q}\left(\stackrel{V}{F}_{q}+\stackrel{V}{F}_{\mathrm{lift}, q}+\stackrel{V}{F}_{\mathrm{Vm}, q}\right),
\end{aligned}
$$

where $\overline{\overline{\tau_{q}}}$ is the stress-strain tensor of the $q$-phase, given as follows:

$$
\overline{\bar{\tau}}=\alpha_{\mathrm{q}} \mu_{\mathrm{q}}\left(\nabla v_{\mathrm{q}}+\nabla v_{\mathrm{q}}^{T}\right)+\alpha_{\mathrm{q}}\left(\lambda_{\mathrm{q}}-\frac{2}{3} \mu_{\mathrm{q}}\right) \nabla \cdot v_{\mathrm{q}} \overline{\bar{I}},
$$

where $\mu_{q}$ and $\lambda_{q}$ are the shear viscosity and volume viscosity of the $q$-phase, respectively; $\vec{F}_{q}$ is the external volume force; $\vec{F}_{\text {lift, } q}$ is the lift; $\vec{F}_{\mathrm{Vm}, q}$ is the virtual mass force; $\vec{R}_{p q}$ is the interaction between the phases; $p$ is the pressure shared by all phases; and $\vec{v}_{p q}$ is the speed of the interphase and is defined as follows: if $\dot{m}_{p q}>0$ (that is, the $p$-phase passes to the quality of the $q$-phase), $\vec{v}_{p q}=\vec{v}_{p}$; if $\dot{m}_{p q}<0$ (that is, the $q$-phase passes to the quality of the $p$-phase), $\vec{v}_{p q}=\vec{v}_{q}$; and $\vec{v}_{p q}=\vec{v}_{q p}$.

2.2.4. Interphase Exchange Coefficient. The momentum exchange between each phase is based on the interphase exchange coefficients, and the determination of the drag coefficient is crucial for fluid-solid simulation.

In the Schiller-Naumann model, the expression of the drag coefficient is

$$
C_{\mathrm{D}}=\left\{\frac{24\left(1+0.15 \mathrm{Re}^{0.687}\right) / \mathrm{Re}}{0.44}, \quad \mathrm{Re} \leq 1000, \mathrm{Re}>1000,\right.
$$

where Re is the Reynolds number.

\section{Numerical Analysis}

3.1. Establishment and Solution of Numerical Analysis Model. To quantitatively understand the impact of various influencing factors on the infiltration instability of filling media, a two-dimensional finite element model was established by using the Fluent software [40]. Each of the three structural models is $1 \mathrm{~m}$ long and $0.5 \mathrm{~m}$ wide. The middle position of the left side of the model has a velocity inlet with a length of $0.02 \mathrm{~m}$; the right interface is a pressure outlet and 
communicates with the atmosphere. Other interfaces, including the fixed particle interface, are all wall surfaces. Quadrilateral meshes are used in all three structural models. Calculation model 1 has a total of 3029 nodes and 2397 units; model 2 has a total of 2974 nodes and 2204 units; and model 3 has a total of 2918 nodes and 2237 units. Figure 2 shows the details of structural model 2.

\subsection{Calculation Results and Discussion}

3.2.1. Water Migration in Different Structures of Soil-Rock Mixture. Through a large number of numerical simulation experiments, the infiltration process of the filling particles under different hydraulic gradients in the filling structure was recognized, and some understanding of the migration of the water phase in the filling structure was obtained. According to the actual situation and the size of the structural model, we have chosen to study a series of speed and time points. Figure 3 shows the distribution of the water phase in each filling structure at different times when the initial water velocity is $1 \mathrm{~m} / \mathrm{s}$ and the diameter of filling particles is $100 \mu \mathrm{m}$.

In the seepage field, the movable particles are subjected to the drag force of the water phase flow. Under the continuous action of the drag force, the static equilibrium state of the particles is destroyed, and the particles begin to move. Taking filling structure 2 as an example, when $t=1 \mathrm{~s}$, because the blocking particles in the front are few, the water infiltration speed in this direction is faster, reaching $1 / 3$ of the entire filling structure. The water phase has taken up a certain amount of space, and the water channel has been formed initially (red area in the figure). In the radial direction, the water phase develops both up and down, but the penetration is slow due to the blocking of the solid particles. At $t=4 \mathrm{~s}$, the range of the water phase shows great development in both axial and radial directions, and the water flow channel further expands; because of the effect of gravity, the water phase permeates faster in the lower region, and the range of the water phase below the inlet is larger than that above the inlet. At $t=10 \mathrm{~s}$, the water phase develops sufficiently and occupies most of the space with only a small amount of movable particles in the upper region; the water phase in the lower area has just reached the bottom wall, while in the upper area, the distance of the water phase from the top wall is $1 / 4$ of the width of the filling structure. The water channel (red area in the figure) reaches the outlet interface, resulting in water inrush and infiltration instability of the filling structure.

Comparing structure 1 , structure 2, and structure 3 , the seepage law of the water phase in different filling structures is found to have similarities and differences. The similarities are that, after the seepage for different times, the seepage mutates, and the structure infiltrates unsteadily. The difference is that structure 1 has the largest distance between the fixed particle phases (soil skeleton) compared with structure 2 and structure 3 , and the structure is relatively loose; the influence of gravity on water seepage is greatest, and the water phase reaches the bottom

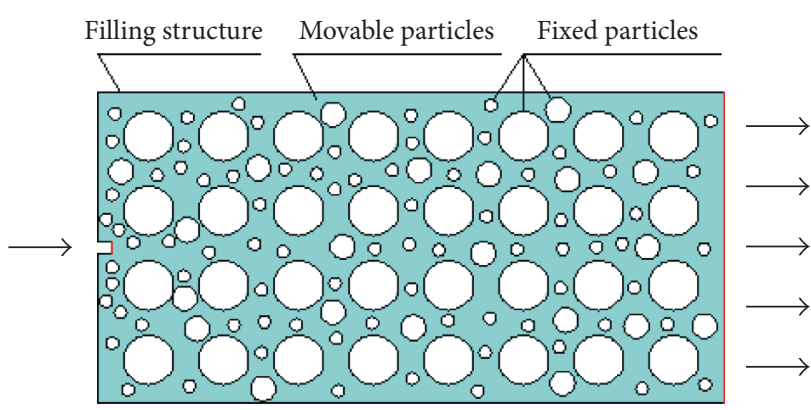

FIGURE 2: Details of structural model 2.

boundary of the structural model first. The distance between the fixed particle phases (soil skeleton) of structure 3 is the smallest, whereas the spread range of the water phase is the largest. Comparing the three models, it is found that the smaller the distance between the fixed particles (soil skeleton), the more uniform the spread of the water phase.

3.2.2. Velocity Vector Distribution of the Water Phase in the Filling Structure. Figure 4 shows the velocity vector distribution of the water phase in each filling structure. The water is found to mainly flow through the pores of the skeleton particles, and at the same time, the movable particles are driven to move until the water flow channel is finally formed [40]. The water velocity near the inlet is relatively large; the closer to the outlet interface, the smaller the water velocity because of the blocking of the particles. The velocity vector of the water phase of structure 2 and structure 3 is mainly near the centerline, and the velocity vector of structure 1 is obliquely downward, which is more obviously influenced by the gravity. Comparing structure 2 and structure 3, relatively more fixed particles are found near the water inlet, and the water flows directly to the front particle gap; because of the large water velocity, the influence of gravity is not obvious at this time. The water velocity of the process of the second half is relatively small, and the influence of gravity is obvious; the water velocity in the lower part is obviously larger than that in the upper part.

\subsubsection{Relationship between the Seepage Time and the Initial} Water Velocity. The initial water velocity at the inlet determines the infiltration duration of the water in the filling structure to a large extent. This paper simulates the migration of water in each filling structure at four different water velocities of $0.5 \mathrm{~m} / \mathrm{s}, 1 \mathrm{~m} / \mathrm{s}, 2 \mathrm{~m} / \mathrm{s}$, and $5 \mathrm{~m} / \mathrm{s}$; Figure 5 shows the relationship curve between the seepage time and initial water velocity in each filling structure. The seepage velocity is found to increase with the increase in the initial water velocity; thus, the seepage time decreases with the increase in water velocity; with the decrease in the initial water velocity, the seepage time increases faster, and a longer seepage time is required. The results agree well with early relevant studies [43]. The distance between the fixed particle phases (soil skeleton) of filling structure 1 is the largest, and 


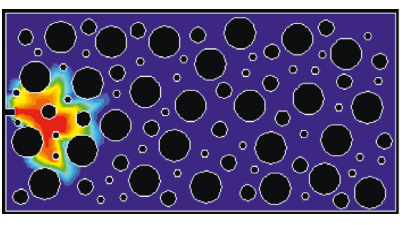

$1 \mathrm{~s}$

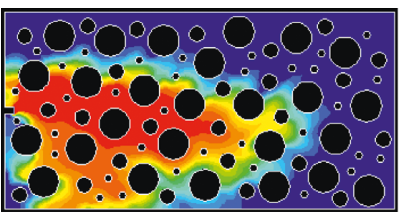

$6 s$

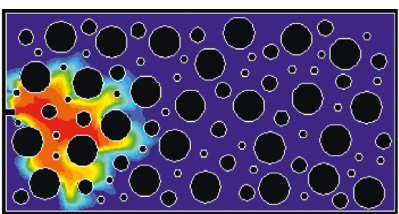

$2 \mathrm{~s}$

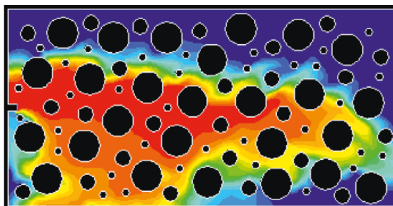

$8 \mathrm{~s}$

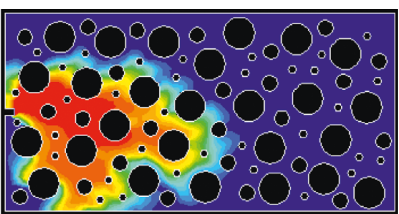

$4 \mathrm{~s}$

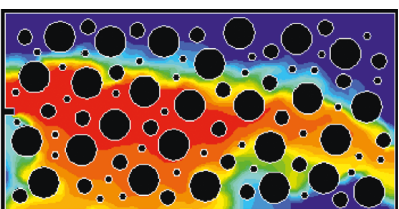

$10 \mathrm{~s}$

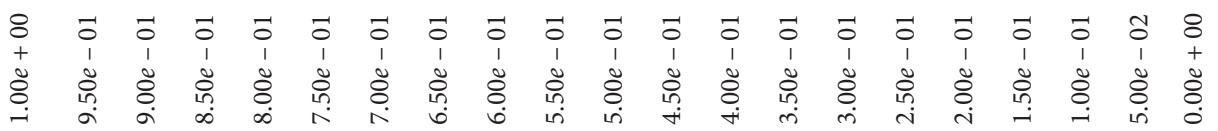

(a)

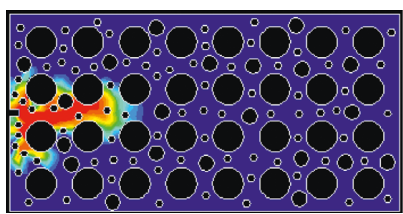

$1 \mathrm{~s}$

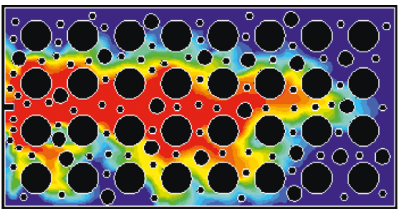

$6 \mathrm{~s}$

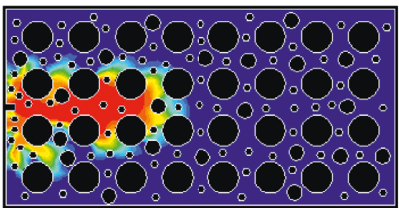

$2 \mathrm{~s}$

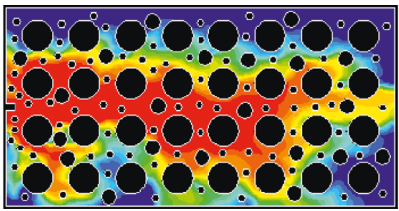

$8 \mathrm{~s}$

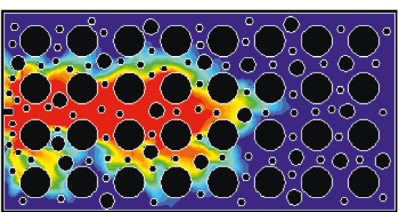

$4 \mathrm{~s}$

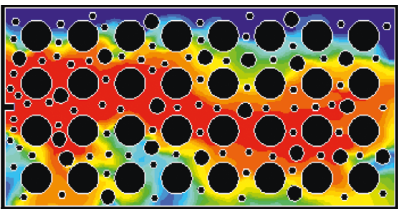

$10 \mathrm{~s}$

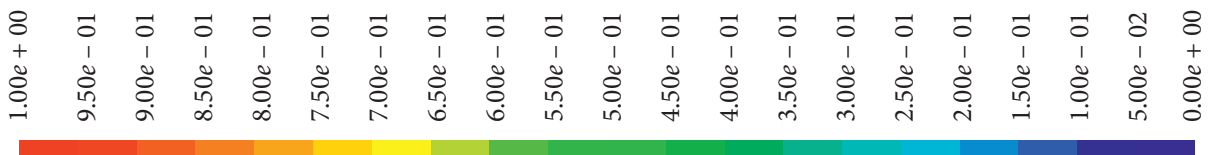

(b)

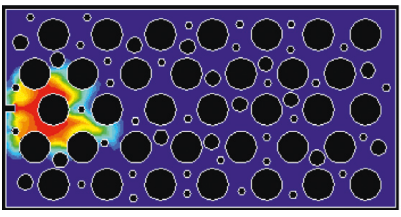

$1 \mathrm{~s}$

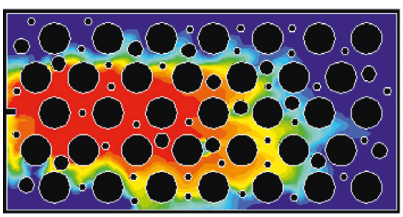

$6 \mathrm{~s}$

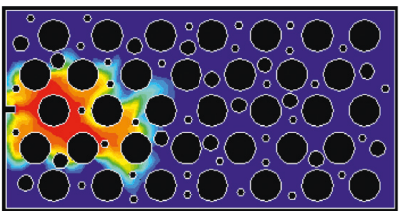

$2 \mathrm{~s}$

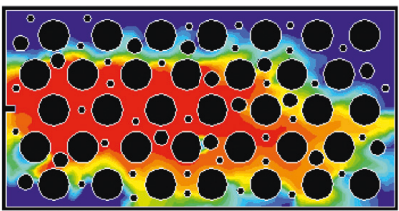

$8 \mathrm{~s}$

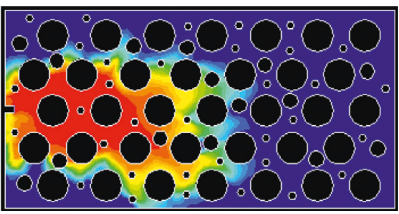

$4 \mathrm{~s}$

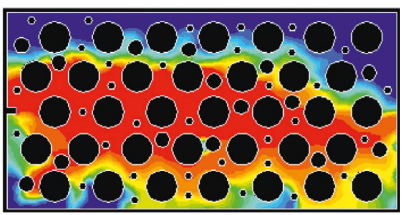

$10 \mathrm{~s}$

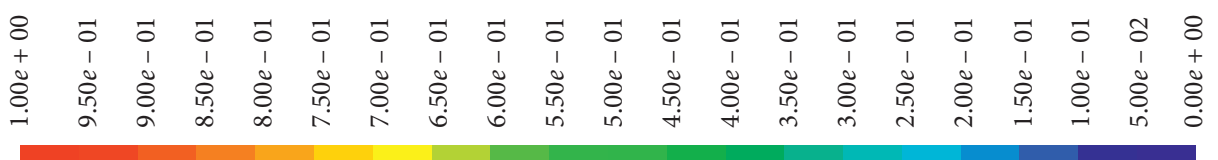

(c)

Figure 3: Migration process of water in different filling structures ( $v=1 \mathrm{~m} / \mathrm{s}$ and $d=100 \mu \mathrm{m})$. (a) Structure 1. (b) Structure 2. (c) Structure 3. 


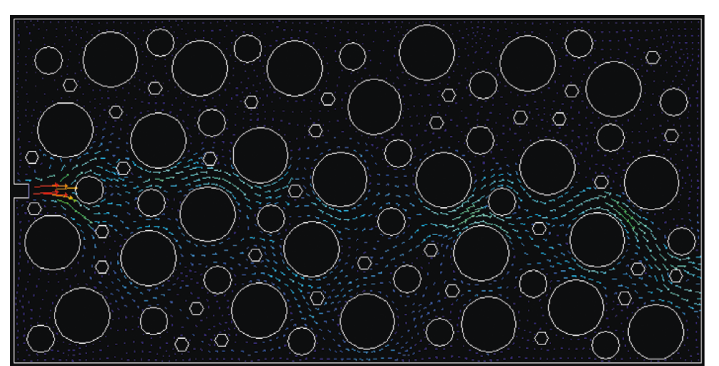

(a)

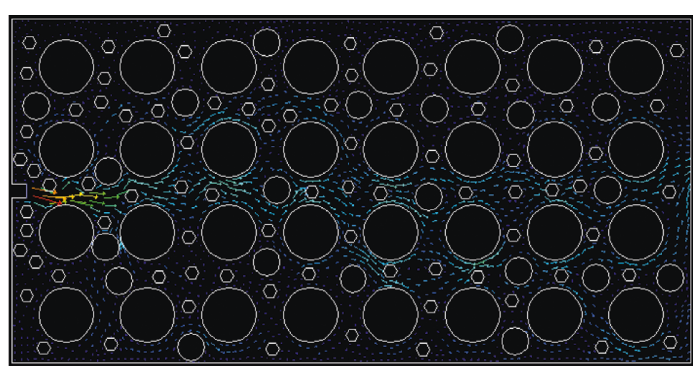

(b)

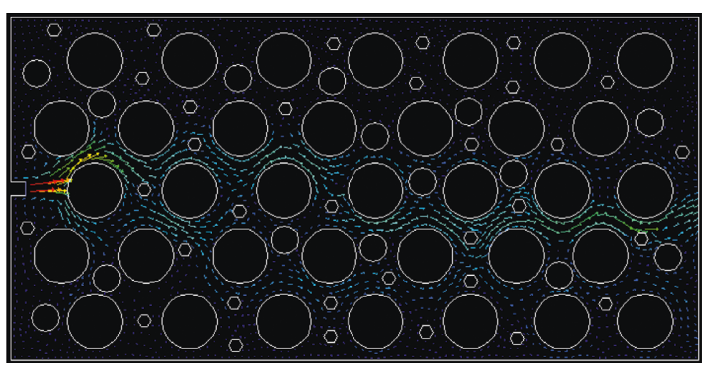

(c)

FIGURE 4: Velocity vector distribution of the water phase in each filling structure. (a) Structure 1. (b) Structure 2. (c) Structure 3.

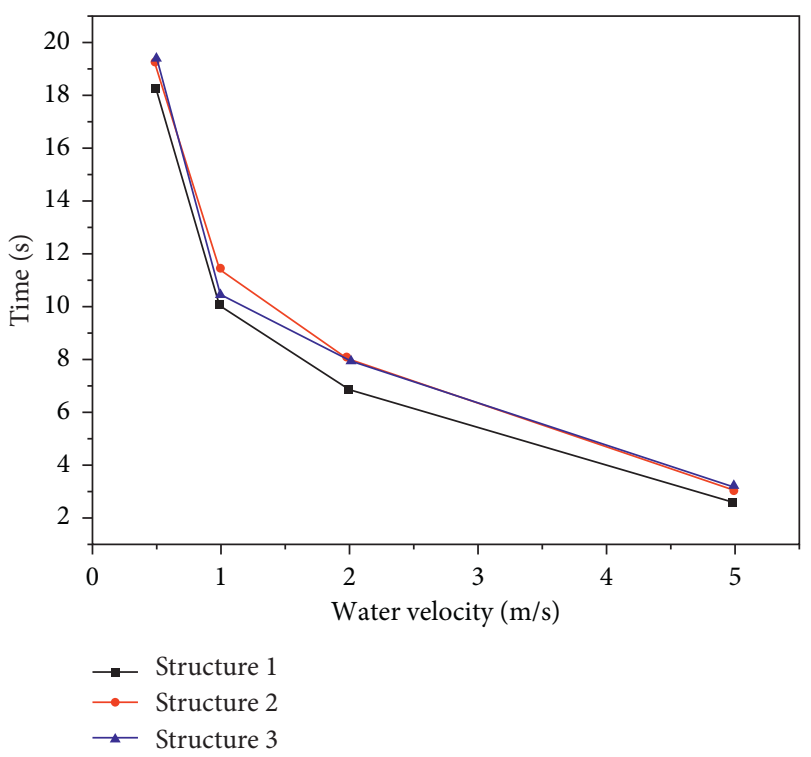

FIgURE 5: Relationship between the seepage time and the initial water velocity in each filling structure.

the filling particles are more easily brought out by the water flow. The figure reveals that the seepage time of structure 1 is the shortest, and the seepage time of structure 2 and structure 3 is almost the same. Comparing comprehensively, it is found that the seepage time has a certain relationship with the filling structure, but the effect of the initial water velocity on the seepage time is far greater than that of the structure. In addition, the greater the initial water velocity, the less obvious the impact of gravity and the more uniform the distribution of water.

Table 1 shows the relationship between the seepage time and the water velocity in three types of filling structures fitted by a logarithmic function and an exponential function and gives the correlation coefficients. The seepage time and the initial water velocity of the three filling structures are found to be better fitted with an exponential function.

3.2.4. Relationship between the Seepage Time and the Dynamic Viscosity. The property of the filling medium in the filling structure has an important influence on the infiltration of the water phase. This paper simulates the migration of the water phase containing particles under different dynamic viscosities in the filled structure; by giving different dynamic viscosities of the filling media, it is possible to simulate the seepage characteristics of the water phase when the filling media are sand and clay. Figure 6 shows the relationship curve between the seepage time and dynamic viscosity in each filling structure when the initial water velocity is $1 \mathrm{~m} / \mathrm{s}$. The figure reveals that the greater the dynamic viscosity, the longer the seepage time, in agreement with the relevant experimental results [44]. The distance between the fixed particle phases (soil skeleton) of filling structure 1 is the largest, and the structure is the loosest; structure 3 is the most compact, and structure 2 is in between the other two. The figure shows that when the dynamic viscosity is the same, the seepage time required by structure 1 is in between those of structure 2 and structure 3 . Thus, the seepage time is related to both the dynamic viscosity and the structure.

Because of limited space, taking structure 2 as an example, Figure 7 shows the migration of the water phase under two different dynamic viscosities. The infiltration process of the water phase under different dynamic viscosities is found to be obviously different. Figure 7(a) shows the water phase infiltration process with sand as the filling medium. Sand particles are loose and have good 
TABLE 1: Fitting function of seepage time and initial water velocity.

\begin{tabular}{lcccc}
\hline \multirow{2}{*}{ Structure } & \multicolumn{2}{c}{ Logarithmic function fitting } & \multicolumn{2}{c}{ Exponential function fitting } \\
& Formula & Correlation coefficient $R^{2}$ & Formula & Correlation coefficient $R^{2}$ \\
\hline 1 & $T=-6.491 \ln (v)+12.012$ & 0.9352 & $T=17.386 e^{-0.394 v}$ & 0.9441 \\
2 & $T=-6.75 \ln (v)+13.131$ & 0.9583 & $T=19.027 e^{-0.376 v}$ & 0.9592 \\
3 & $T=-6.629 \ln (v)+12.917$ & 0.9212 & $T=18.159 e^{-0.358 v}$ & 0.9324 \\
\hline
\end{tabular}

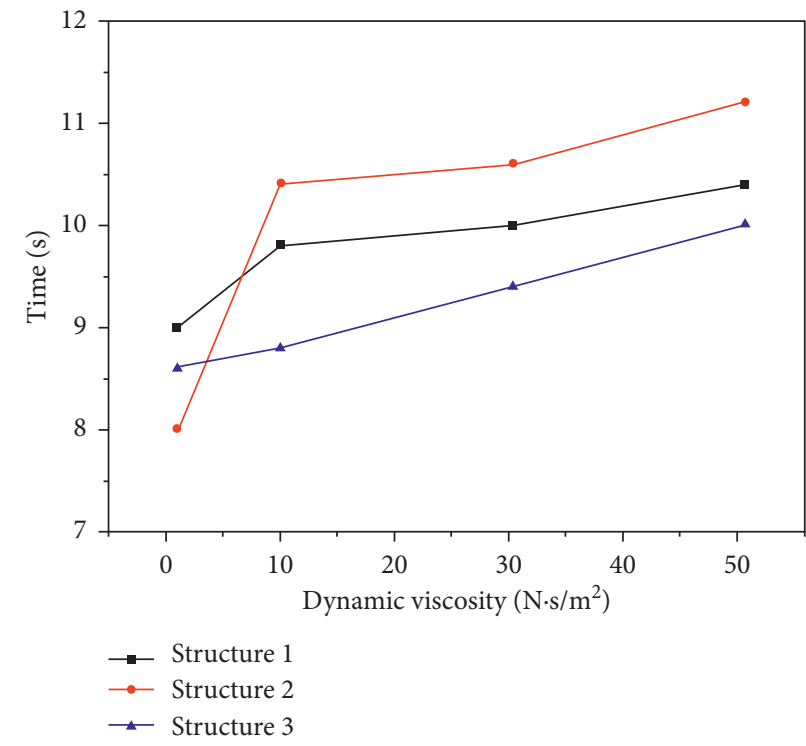

FIgURE 6: Relationship between the seepage time and the dynamic viscosity in each filling structure.

permeability, so they are obviously influenced by gravity; under the action of gravity, the water phase first spreads obliquely below the filling structure. The water phase infiltrates rapidly in loose sand, reaches the lower boundary at $3 \mathrm{~s}$, and initially forms a seepage channel along the lower boundary at $6 \mathrm{~s}$. Figure $7(\mathrm{~b})$ shows the water phase infiltration process with clay as the filling medium. The interaction between particles of clay is much larger than that between those of sand. The greater the dynamic viscosity, the stronger the interaction between particles. The overall infiltration rate of the water phase is slow, and it is also difficult to infiltrate to the radial direction; the influence of gravity is not obvious.

\section{Conclusions}

To reveal the mechanism of water inrush in a fault tunnel and study the influence of different structures on the seepage process, a filling structure composed of the soil skeleton (fixed particles), mobile particles phase, and water phase was constructed. Fluent software was used to study the migration of the water phase in the filling structure. The migration experiments of the water phase in three different filling structures under different water velocities and dynamic viscosities were performed. The distribution of the water phase in different filling structures and the variation law of seepage time with initial water velocity and dynamic viscosity were obtained. The main conclusions are as follows:
(1) The larger the distance between the fixed particles (soil skeleton) in the filling structure, the looser the structure and the greater the influence of gravity on the water phase seepage; the smaller the distance between the fixed particle phases (soil skeleton), the greater the spread range of the water phase and the more uniform the spread of the water phase.

(2) The water flow mainly formed the seepage channel in the direction of the large gap of skeleton particles. In the process of water phase seepage, the influence of gravity is not obvious because of the large water velocity in the process of the first half; the water velocity in the process of the second half is smaller, and the influence of gravity is obvious.

(3) The seepage time decreases with the increase in the initial water velocity. The smaller the initial water velocity, the faster the increase of seepage time. The seepage time and initial water velocity can be fitted by an exponential function. The effect of the initial water velocity on seepage time is much greater than that of the structure.

(4) The seepage time increases with the increase in the dynamic viscosity. The greater the dynamic viscosity, the greater the interaction between the particles, the stronger the water-blocking ability, and the longer the seepage time. When the dynamic viscosity is certain, the influence of structure on the seepage time is obvious. 


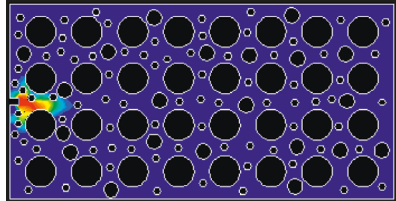

$0.2 \mathrm{~s}$

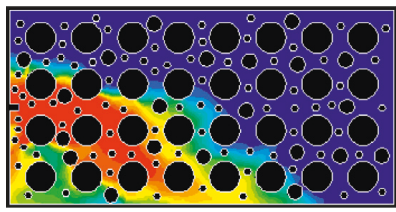

$4 \mathrm{~s}$

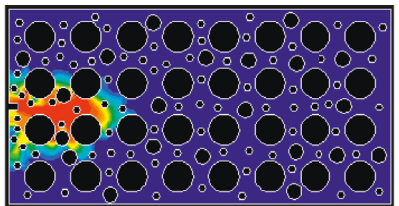

$1 \mathrm{~s}$

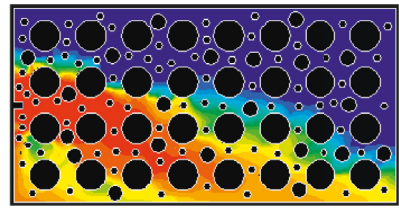

$6 s$

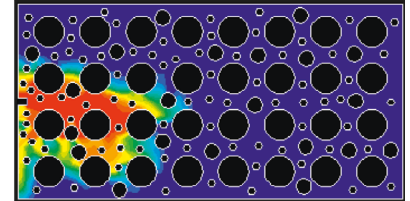

$2 \mathrm{~s}$

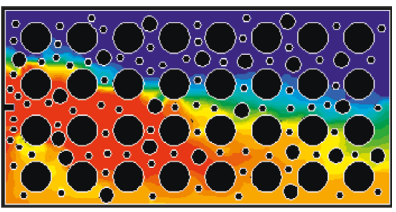

$8 \mathrm{~s}$

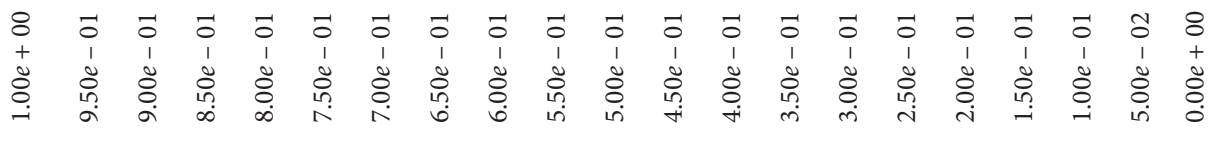

(a)

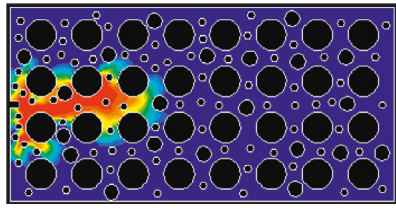

$2 \mathrm{~s}$

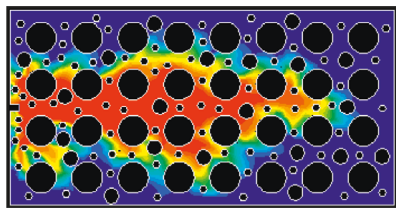

8

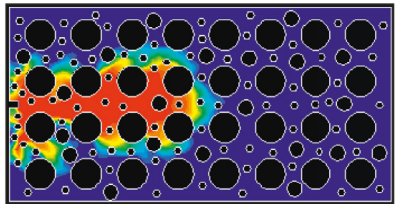

$4 \mathrm{~s}$

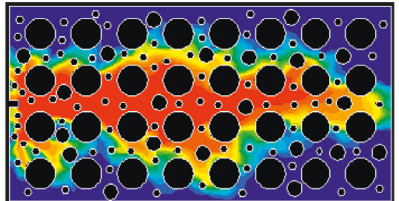

$10 \mathrm{~s}$

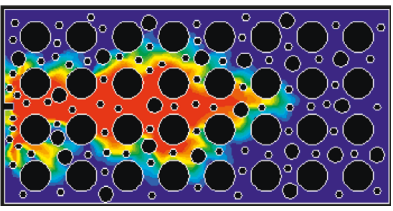

$6 \mathrm{~s}$

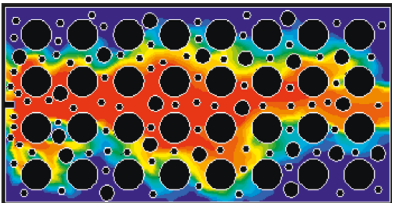

$12 \mathrm{~s}$

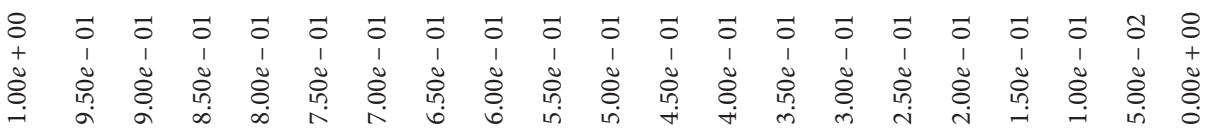

(b)

Figure 7: Migration process of water in filling structure 2 under different dynamic viscosities: (a) $\mu=1 \mathrm{~N} \cdot \mathrm{s} / \mathrm{m}^{2}$; (b) $\mu=30 \mathrm{~N} \cdot \mathrm{s} / \mathrm{m}^{2}$.

\section{Conflicts of Interest}

The authors declare that there are no conflicts of interest regarding the publication of this paper.

\section{Acknowledgments}

Financial supports from the National Natural Science Foundation of China (Nos. 41572263, 51309222, 11502282, and 51504247) and the Fundamental Research Funds for the Central Universities (2017XKQY074) are sincerely acknowledged.

\section{References}

[1] J. Zhang and S. Peng, "Water inrush and environmental impact of shallow seam mining," Environmental Geology, vol. 48, no. 8, pp. 1068-1076, 2005.
[2] K. R. Hong, "Development and prospects of tunnels and underground works in China in recent two years," Tunnel Construction, vol. 37, no. 2, pp. 123-134, 2017.

[3] L. P. Li, T. Lei, S. C. Li, Q. Q. Zhang, Z. H. Xu, and S. S. Shi, "Risk assessment of water inrush in karst tunnels and software development," Arabian Journal of Geosciences, vol. 8, no. 4, pp. 1843-1854, 2015.

[4] S. S. Shi, Study on seepage failure mechanism and risk control of water inrush induced by filled disaster structure in deep-long tunnel and engineering applications, Ph.D. thesis, Shandong University at Jinan, Jinan, China, 2014.

[5] L. P. Li, T. Lei, S. C. Li, Z. H. Xu, Y. G. Xue, and S. S. Shi, "Dynamic risk assessment of water inrush in tunnelling and software development," Geomechanics and Engineering, vol. 9, no. 1, pp. 57-81, 2015.

[6] X. P. Li and Y. N. Li, "Research on risk assessment system for water inrush in the karst tunnel construction based on GIS: case study on the diversion tunnel groups of the Jinping II 
hydropower station," Tunnelling and Underground Space Technology, vol. 40, no. 2, pp. 182-191, 2014.

[7] L. P. Li, Z. Q. Zhou, S. C. Li, Y. G. Xue, Z. H. Xu, and S. S. Shi, "An attribute synthetic evaluation system for risk assessment of floor water inrush in coal mines," Mine Water and the Environment, vol. 34, no. 3, pp. 288-294, 2014.

[8] D. L. Dong, "Water-inrush assessment using a GIS-based bayesian network for the 12-2 coal seam of the kailuan donghuantuo coal mine in China," Mine Water and the Environment, vol. 31, no. 2, pp. 353-360, 2012.

[9] L. P. Li, W. F. Tu, S. S. Shi, J. X. Chen, and Y. H. Zhang, "Mechanism of water inrush in tunnel construction in karst area," Geomatics Natural Hazards and Risk, vol. 7, no. 1, pp. 35-46, 2016.

[10] Y. C. Wang, W. Jing, L. Y. Yu, H. J. Su, and N. Luo, "Set pair analysis for risk assessment of water inrush in karst tunnels," Bulletin of Engineering Geology and the Environment, vol. 76, no. 3, pp. 1199-1207, 2017.

[11] Y. C. Wang, X. Yin, F. Geng, H. W. Jing, H. J. Su, and R. C. Liu, "Risk assessment of water inrush in karst tunnels based on the efficacy coefficient method," Polish Journal of Environmental Studies, vol. 26, no. 4, pp. 1765-1775, 2017.

[12] Y. C. Wang, X. Yin, H. W. Jing, R. C. Liu, and H. J. Su, "A novel cloud model for risk analysis of water inrush in karst tunnels," Environmental Earth Sciences, vol. 75, no. 22, pp. 1-13, 2016.

[13] H. B. Bai, D. Ma, and Z. Q. Chen, "Mechanical behavior of groundwater seepage in karst collapse pillars," Engineering Geology, vol. 164, no. 18, pp. 101-106, 2013.

[14] D. Ma, M. Rezania, H. S. Yu, and H. B. Bai, "Variations of hydraulic properties of granular sandstones during water inrush: effect of small particle migration," Engineering Geology, vol. 217, pp. 61-70, 2017.

[15] J. A. Wang and H. D. Park, "Fluid permeability of sedimentary rocks in a complete stress-strain process," Engineering Geology, vol. 63, no. 3-4, pp. 291-300, 2002.

[16] Z. H. Xu, S. C. Li, L. P. Li, J. Chen, and S. S. Shi, "Construction permit mechanism of karst tunnels based on dynamic assessment and management of risk," Chinese Journal of Geotechnical Engineering, vol. 33, no. 11, pp. 1714-1725, 2011.

[17] Y. C. Wang, H. W. Jing, H. J. Su, and J. Y. Xie, "Effect of a fault fracture zone on the stability of tunnel-surrounding rock," International Journal of Geomechanics, vol. 17, no. 6, article 04016135, 2017.

[18] R. W. Liu and J. H. Sun, "The large delaying water bursting in Nanzhuang mine and the reason analysis," in Proceedings of National Conference of Mine Hydro-geology, pp. 48-52, Tai'an, Shandong, China, 1992.

[19] H. G. Ni and G. Y. Luo, "Study on the mechanism of preferred plane of water hazard in coal mine," Journal of China Coal Society, vol. 25, no. 5, pp. 518-521, 2000.

[20] Q. Wu, B. Zhu, J. M. Li, Y. Q. Hong, and Z. J. Qian, "Numerical simulation of lagging water inrush mechanism of rock roadways near fault zone," Journal of China University of Mining and Technology, vol. 37, no. 6, pp. 780-785, 2008.

[21] Q. Wu, B. Zhu, and S. Q. Liu, "Flow-solid coupling simulation method analysis and time identification of lagging waterinrush near mine fault belt," Chinese Journal of Rock Mechanics and Engineering, vol. 30, no. 1, pp. 93-104, 2011.

[22] L. C. Li, C. A. Tang, Z. Z. Liang, T. H. Ma, and Y. B. Zhang, "Numerical analysis of pathway formation of groundwater inrush from faults in coal seam floor," Chinese Journal of Rock Mechanics and Engineering, vol. 28, no. 2, pp. 290-297, 2009.

[23] L. C. Li, C. A. Tang, Y. J. Zuo, G. Li, and C. Liu, "Mechanism of hysteretic ground water inrush from coal seam floor with karstic collapse columns," Journal of China Coal Society, vol. 34, no. 9, pp. 1212-1216, 2009.

[24] F. AL, S. Hedan, V. Valle, D. Pret, J. Cabrera, and P. Cosenza, "Multi-scale study on the deformation and fracture evolution of clay rock sample subjected to desiccation," Applied Clay Science, vol. 132-133, pp. 251-260, 2016.

[25] W. J. Xu, S. Wang, H. Y. Zhang, and Z. L. Zhang, "Discrete element modelling of a soil-rock mixture used in an embankment dam," International Journal of Rock Mechanics and Mining Sciences, vol. 86, pp. 141-156, 2016.

[26] S. Pietruszczak and P. Guo, "Description of deformation process in inherently anisotropic granular materials," International Journal for Numerical and Analytical Methods in Geomechanics, vol. 37, no. 5, pp. 478-490, 2013.

[27] Z. Mahmood and K. Iwashita, "Influence of inherent anisotropy on mechanical behavior of granular materials based on DEM simulations," International Journal for Numerical and Analytical Methods in Geomechanics, vol. 34, no. 8, pp. 795-819, 2010.

[28] A. A. Pena, R. Garcia-Rojo, and H. J. Herrmann, "Influence of particle shape on sheared dense granular media," Granular Matter, vol. 9, no. 3-4, pp. 279-291, 2007.

[29] Z. L. Zhang, W. J. Xu, W. Xia, and H. Y. Zhang, "Large-scale in-situ test for mechanical characterization of soil-rock mixture used in an embankment dam," International Journal of Rock Mechanics and Mining Sciences, vol. 86, pp. 317-322, 2016.

[30] Z. Liu, J. Shao, W. Xu, and C. Shi, "Estimation of elasticity of porous rock based on mineral composition and microstructure," Advances in Materials Science and Engineering, vol. 2013, Article ID 512727, 10 pages, 2013.

[31] Y. G. Yang, F. Gao, H. M. Cheng, Y. M. Lai, and X. X. Zhang, "Researches on the constitutive models of artificial frozen silt in underground engineering," Advances in Materials Science and Engineering, vol. 2014, Article ID 902164, 8 pages, 2014.

[32] G. Bourkas, I. Prassianakis, V. Kytopoulos, E. Sideridis, and C. Younis, "Estimation of elastic moduli of particulate composites by new models and comparison with moduli measured by tension, dynamic, and ultrasonic tests," Advances in Materials Science and Engineering, vol. 2010, Article ID 891824, 13 pages, 2010.

[33] H. Yang, Z. Zhou, X. C. Wang, and Q. F. Zhang, "Elastic modulus calculation model of a soil-rock mixture at normal or freezing temperature based on micromechanics approach," Advances in Materials Science and Engineering, vol. 2015, Article ID 576080, 10 pages, 2015.

[34] N. Coli, P. Berry, and D. Boldini, "In situ non-conventional shear tests for the mechanical characterisation of a bimrock," International Journal of Rock Mechanics and Mining Sciences, vol. 48, no. 1, pp. 95-102, 2011.

[35] H. Y. Zhang, W. J. Xu, and Y. Z. Yu, "Triaxial tests of soil-rock mixtures with different rock block distributions," Soils and Foundations, vol. 56, no. 1, pp. 44-56, 2016.

[36] W. C. Zhu and C. H. Wei, "Numerical simulation on mininginduced water inrushes related to geologic structures using a damage-based hydromechanical model," Environmental Earth Sciences, vol. 62, no. 1, pp. 43-54, 2011.

[37] J. Saul Caine, J. P. Evans, and C. B. Forster, "Fault zone architecture and permeability structure," Geology, vol. 24, no. 11, pp. 1025-1028, 1996.

[38] H. Y. Li, H. J. Zhang, S. C. Li, R. T. Liu, Z. Zheng, and J. W. Bai, "The seepage-flowing conversion mechanism of the fault lagging water inrush and its numerical simulation," 
Journal of Mining and Safety Engineering, vol. 34, no. 2, pp. 323-329, 2017.

[39] T. C. Li, L. X. Lv, H. L. Duan, and W. Chen, "Water burst mechanism of deep buried tunnel passing through weak water-rich zone," Journal of Central South University (Science and Technology), vol. 47, no. 10, pp. 3469-3476, 2016.

[40] Y. C. Wang, F. S. Meng, F. Geng, H. W. Jing, and N. Zhao, "Investigating water permeation through the soil-rock mixture in underground engineering," Polish Journal of Environmental Studies, vol. 26, no. 4, pp. 1777-1788, 2017.

[41] X. J. Zhou, Y. X. Jie, and G. X. Li, "Numerical simulation of piping based on coupling seepage and pipe flow," Rock and Soil Mechanics, vol. 30, no. 10, pp. 3154-3158, 2009.

[42] F. Jiang, Advanced Application and Case Analysis of Fluent, Tsinghua University Press, Beijing, China, 2008.

[43] L. Z. Wang, Z. Q. Chen, H. L. Kong, and X. Y. Ni, "An experimental study of the influence of seepage pressure and initial porosity on variable mass seepage for broken mudstone," Journal of Mining and Safety Engineering, vol. 31, no. 3, pp. 462-468, 2014.

[44] Y. B. Pei, W. P. LI, Q. Q. Liu, Q. Q. Wang, and S. S. Yan, "Research on permeability of earth-rock aggregate in weathering zone on top Ordovician," Coal Engineering, vol. 48, no. 10, pp. 92-95, 2016.

[45] Y. B. Pei, W. P. LI, Q. Q. Liu, Q. Q. Wang, and S. S. Yan, "Research on permeability of earth-rock aggregate in weathering zone on top Ordovician," Coal Engineering, vol. 48, no. 10, pp. 92-95, 2016. 


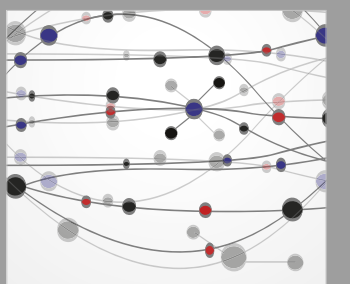

The Scientific World Journal
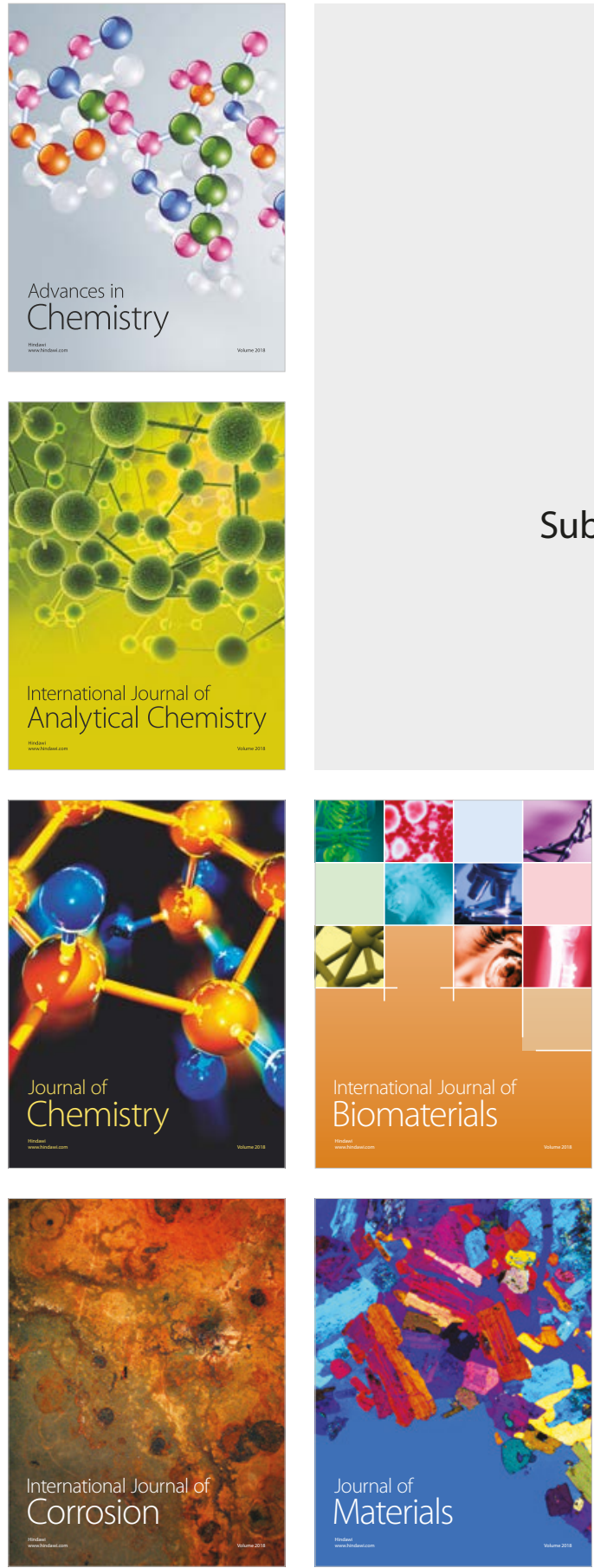

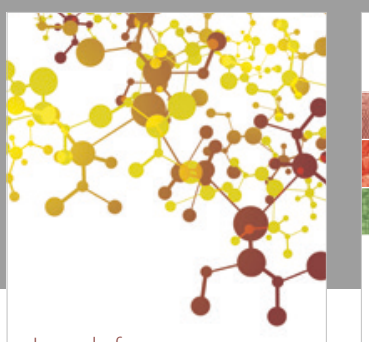

Journal of

Applied Chemistry
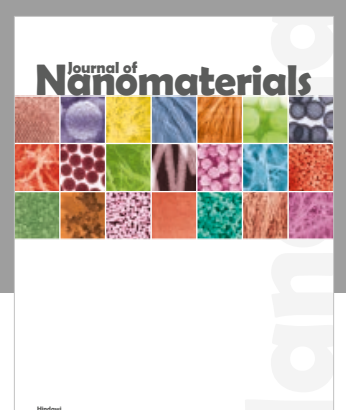

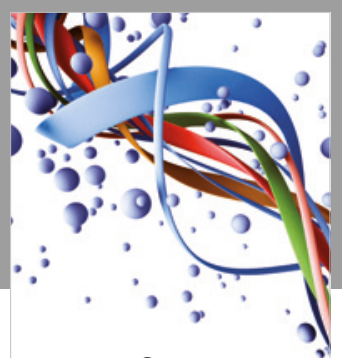

Scientifica

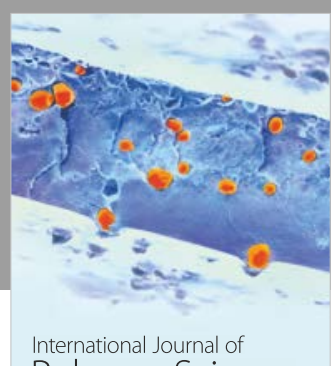

Polymer Science

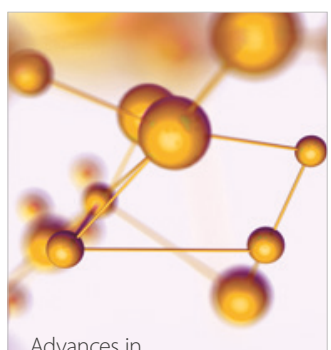

Physical Chemistry
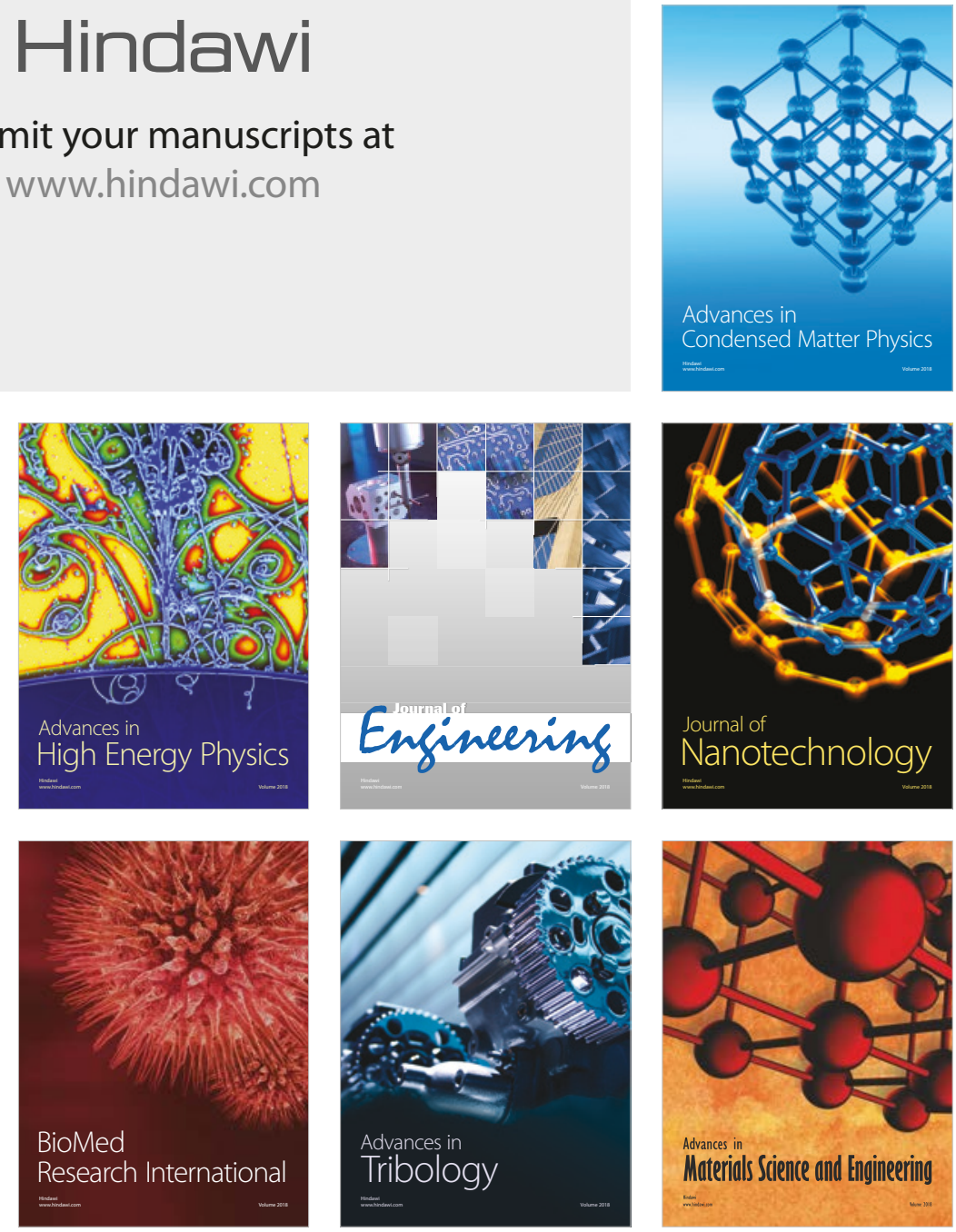